\title{
Remote hydroacoustic sensing of large icebergs in the southern Indian Ocean: Implications for iceberg monitoring
}

\author{
L. G. Evers, ${ }^{1,2}$ D. N. Green, ${ }^{3}$ N. W. Young, ${ }^{4,5}$ and M. Snellen ${ }^{6}$ \\ Received 18 July 2013; revised 23 August 2013; accepted 26 August 2013.
}

[1] Hydroacoustic signals generated by drifting icebergs that crack, disintegrate, and collide were identified on two hydrophone arrays in the Indian Ocean. These hydrophone arrays are deployed in the Sound Fixing and Ranging channel, enabling the detection of small sources over ranges of several thousand kilometers due to the low attenuation. Source locations estimated from the signal bearings at the arrays are used to monitor two very large icebergs, C20 and B17B. Spatial and temporal correlation of the location estimates with satellite observations confirm that the icebergs can be hydroacoustically resolved. Hydroacoustic generation rates at both $\mathrm{C} 20$ and $\mathrm{B} 17 \mathrm{~B}$ are highest at times of observed breakup. For C20, which underwent continuous breakup, clusters of events to the southeast of the main iceberg show that hydroacoustic observations can identify trails of icebergs that calved from the main berg whose dimensions are less than that easily resolved by moderate resolution satellite monitoring. Citation: Evers, L. G., D. N. Green, N. W. Young, and M. Snellen (2013), Remote hydroacoustic sensing of large icebergs in the southern Indian Ocean: Implications for iceberg monitoring, Geophys. Res. Lett., 40, doi:10.1002/grl.50914.

\section{Introduction}

[2] The International Monitoring System (IMS), designed as one of the verification measures for a Comprehensive Nuclear-Test-Ban Treaty (CTBT), includes hydroacoustic stations to monitor the oceans for nuclear test explosions [De Groot-Hedlin and Orcutt, 2001]. Acoustic waves travel efficiently through the SOFAR (Sound Fixing and Ranging) channel, with an average depth of the axis at between 1 and $2 \mathrm{~km}$ water depth [Jensen et al., 2000], enabling the detection of low energy events over long ranges. For example, the IMS triplet hydrophone arrays deployed in the SOFAR channel have detected signals from explosions of less than $40 \mathrm{~kg}$ Trinitrotoluene (TNT) at ranges up to $16,000 \mathrm{~km}$ [Prior et al., 2011].

Additional supporting information may be found in the online version of this article.

${ }^{1}$ Seismology Division, KNMI, De Bilt, Netherlands.

${ }^{2}$ Department of Geoscience and Engineering, Faculty of Civil Engineering and Geosciences, TU Delft, Delft, Netherlands.

${ }^{3}$ AWE Blacknest, Reading, UK.

${ }^{4}$ Australian Antarctic Division, Kingston, Tasmania, Australia.

${ }^{5}$ Antarctic Climate and Ecosystems Cooperative Research Centre, Hobart, Tasmania, Australia.

${ }^{6}$ Acoustic Remote Sensing Group, Faculty of Aerospace Engineering, TU Delft, Delft, Netherlands.

Corresponding author: L. G. Evers, Seismology Division, KNMI, PO Box 201, 3730 AE De Bilt, Netherlands. (evers@knmi.nl)

C2013. American Geophysical Union. All Rights Reserved. 0094-8276/13/10.1002/grl.50914
[3] Although the IMS was designed to detect explosions, the hydrophone arrays also detect signals from earthquakes [Guilbert et al., 2005], underwater volcanoes [Green et al., 2013], calving ice and icebergs [Talandier et al., 2002; Chapp et al., 2005; Talandier et al., 2006], marine mammals, and seismic surveys [Prior et al., 2012].

[4] Previous studies of ice-generated signals concentrated on events within the southern Indian Ocean (below $60^{\circ} \mathrm{S}$ ) and identified specific events interpreted as grounded or drifting icebergs [Talandier et al., 2002; Li and Gavrilov, 2006; Gavrilov and Li, 2011] or activity at outlet glaciers along the coast of east Antarctica [Chapp et al., 2005]. In contrast, our study focuses on signals of drifting icebergs in the southern Indian Ocean $\left(\sim 46^{\circ} \mathrm{S}\right.$ to $\left.56^{\circ} \mathrm{S}\right)$; we use events derived from all detections made by two IMS stations located in the Indian Ocean.

[5] From the detection lists, we identify events occurring during the Austral summer that can be associated with the movement and breakup of major icebergs, i.e., a semicontinuous sequence of discrete events. The results show that hydroacoustic signals can complement satellite monitoring of very large icebergs: the hydroacoustic generation rate increases during the iceberg's breakup, hydroacoustic signals identify the iceberg at times after the iceberg becomes too small to be tracked by satellite, and locations of hydroacoustic events identify regions of smaller icebergs generated by the breakup of the main iceberg.

\section{Hydroacoustic Detections}

[6] Three IMS stations are situated in the Indian Ocean, named $\mathrm{H} 01, \mathrm{H} 04$, and $\mathrm{H} 08$. H01, located off the coast of southwest Australia (H01W), consists of one triplet array. H08 is configured with two triplet arrays, one to the north $(\mathrm{H} 08 \mathrm{~N})$ and one to the south (H08S) of Diego Garcia (see Figure 1). H04 is currently being reconstructed; due to the low data availability at this station, it is not used.

[7] At the International Data Center, an algorithm automatically detects coherent acoustic waves that propagate across the arrays, by evaluating the difference between short time average power (STA) and long time average power (LTA), i.e., an STA/LTA algorithm. Such detections occur at the maximum energy in the signal, which is typically not the onset in the emergent waveforms resulting from long range propagation. For each detection, the back azimuth to the event is determined from the normal to the wavefront and measured with respect to the north, i.e., $0^{\circ}$ equals a source to the north. This is done by evaluating the arrival time differences at the individual hydrophones in the array; the time differences are obtained from cross correlations in a frequency range from 3 to $100 \mathrm{~Hz}$. These automatic detections and back azimuth estimates are used in this study. 


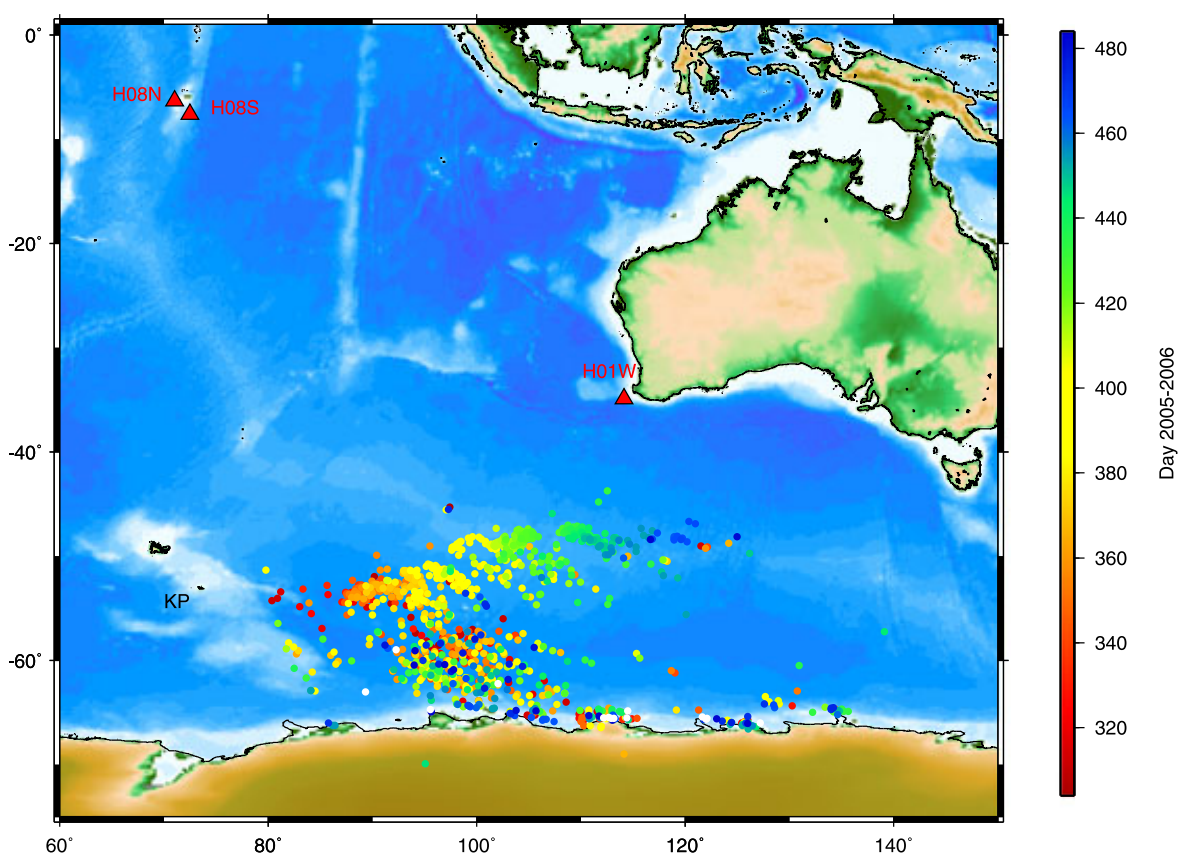

Figure 1. Map showing the location of H08S, H08N, and H01W in the Indian Ocean (KP=Kerguelen Plateau). The colored dots are locations estimated from detections at H08S and H01W. The colors indicate the day in 2005 and $2006(+365)$.

[8] Figure 2 shows the retrieved back azimuths as a function of time. Four remarkable features are visible. (1) H08S and $\mathrm{H} 01 \mathrm{~W}$ measured hydroacoustic waves from the Sumatra region. This is seismic energy from earthquakes that is converted to hydroacoustic energy at the ocean floor and then enters the SOFAR channel. Clearly visible are the large Sumatran earthquakes of 26 December 2004, 28 March 2005, and 11 April 2012. (2) H08N also detects seismic activity from the Carlsberg Ridge, around $330^{\circ}$ [Prior et al., 2012]. Propagation of energy from these sources is blocked to H08S by the atolls of the British Indian Ocean Territory surrounding Diego Garcia. (3) At both H01W and H08, a seasonal cycle is observed in detections from the south (back azimuths between $140^{\circ}$ and $220^{\circ}$ ). High detection rates are observed at the beginning of the year (January to June), while fewer detections are made during the second half of the year. In addition, H08N detects very little energy arriving from the south and east due to the presence the atolls. (4) Within the periods of high activity from the south, the back azimuths change as a function of time which indicates a moving source. Such a sequence is most pronounced during late 2005 and early 2006 at both H08S and H01W (see right frames of Figure 2).

[9] Based on these observations, it is hypothesized that the signals from a moving source originate from calving and colliding icebergs near Antarctica during the Austral summer. However, the back azimuths of the moving feature indicate an eastward movement; this is in contrast to the north-westward movement of icebergs observed near the coast [e.g., Gavrilov and Li, 2011]. South of the Antarctic Divergence, which in this part of the Antarctic region lies roughly along latitude $64^{\circ} \mathrm{S}$, the broad movement of the ocean is to the west, and most strongly in the Antarctic Slope Current (ASC) which occurs close to the break in slope of the seafloor at the outer edge of the continental shelf. In the following sections, we show that the observed eastward propagating detections are associated with a very large iceberg located north of this region, traveling within the eastward Antarctic Circumpolar Current (ACC) in the southern Indian Ocean.

\section{Localizing the Sources}

[10] The arrival times and estimated back azimuths are used to associate detections at $\mathrm{H} 01 \mathrm{~W}$ and $\mathrm{H} 08 \mathrm{~S}$, and the back azimuths alone provide an estimate of the geographical source location. We focus on an area of the southern Indian Ocean between the latitude range of $40^{\circ} \mathrm{S}$ to $70^{\circ} \mathrm{S}$ and the longitude range of $70^{\circ} \mathrm{E}$ to $140^{\circ} \mathrm{E}$. The relevant ranges of back azimuths at $\mathrm{H} 01 \mathrm{~W}$ and $\mathrm{H} 08 \mathrm{~S}$ are $150^{\circ}-230^{\circ}$ and $140^{\circ}-174^{\circ}$, respectively. As noted by Chapp et al. [2005], hydroacoustic energy from Antarctica is partially blocked on paths to H08S by the Kerguelen Plateau (see Figure 1). The intersection of a pair of back azimuths from H01W and $\mathrm{H} 08 \mathrm{~S}$ defines a location that may be the origin of an acoustic event. This location method with cross bearings solves a simple geometric problem. Arrival time information is used to check whether any location is credible. The travel times from the location to both stations are calculated assuming a constant acoustic velocity of $1475 \mathrm{~m} / \mathrm{s}$ [Chapp et al., 2005]. Two estimates of the source origin time of the event are then obtained from the H08S and H01W arrival times; the difference between these origin time estimates is termed $\Delta t$.

[11] Two dominant factors generate uncertainties in the calculated origin times, resulting in nonzero $\Delta t$ values. First, errors in the velocity model will result in systematic biases in the calculated propagation time. Second, uncertainties in the arrival time pick due to waveform amplitude fluctuations will generate random scatter in the origin time. As icebergrelated events generate emergent waveforms with durations of up to $50 \mathrm{~s}$ at distant stations, arrival time uncertainties will result in $\Delta t$ values of tens of seconds. 



Figure 2. The back azimuths of detections at $\mathrm{H} 08 \mathrm{~S}, \mathrm{H} 08 \mathrm{~N}$, and $\mathrm{H} 01 \mathrm{~W}$ as a function of time. The left frames show a period ranging from 01 July 2004 00:00:00 to 21 June 2012 23:59:59, the right frames show the period of 01 July 2005 00:00:00 to 01 July 2006 23:59:59. Color coded are the number of events binned in intervals of $1 \mathrm{~h}$ and $5^{\circ}$ (left) and $1 \mathrm{~h}$ and $2^{\circ}$ (right).

[12] We apply a criterion for simultaneity where $\Delta t$ is less than a threshold. The range of absolute values of $\Delta t$ for the period between 01 November 2005 to 01 May 2006 have a unimodal distribution centered at approximately $-30 \mathrm{~s}$ (Figure S1 in the supporting information). This offset from 0 s identifies that the single velocity model is too simple; the propagation velocity to H08S is too low. Therefore, a normal mode propagation model is used to estimate the velocity to $\mathrm{H} 08 \mathrm{~S}$ and $\mathrm{H} 01 \mathrm{~W}$ from an average source location $51^{\circ} \mathrm{S}$, $105^{\circ} \mathrm{E}$ [Jensen et al., 2000; Green et al., 2013], where the axis depth is about $200 \mathrm{~m}$. The resulting velocities are 1485 and $1480 \mathrm{~m} / \mathrm{s}$ for H08S and H01W, respectively. The corresponding $\Delta t$ distribution now has its median at $-7 \mathrm{~s}$, with a standard deviation of $17 \mathrm{~s}$ (Figure S1), which will be used as $\Delta t$ threshold. Modeling also showed that the energy from a (near-surface) source couples into the SOFAR channel as long as its radiation pattern is not too directive [Snellen et al., 2012].

[13] The colored dots in Figure 1 show the resulting locations as a function of time. The 1135 events were located for the 2005-2006 Austral summer. The events are concentrated in three regions: (1) an area north of $58^{\circ} \mathrm{S}$ (not previously reported), (2) a region south of $58^{\circ} \mathrm{S}$ off the coast of Antarctica (similar to the results of Gavrilov and $\mathrm{Li}$ [2011]), and (3) a region close to the coast of Antarctica (in agreement with the results of Chapp et al. [2005]). The events in (2) and (3) are randomly distributed over time; however, those in (1) exhibit a systematic displacement from west to east. This movement is consistent with the observed H01W and H08S back azimuth variations. Few events are located on the continent of Antarctica, which gives confidence in the chosen approach.

\section{Identifying the Sources}

[14] Satellite measurements of microwave backscatter allow icebergs to be identified and tracked [Stuart and Long, 2011]; the colored circles with solid black rims in Figure 3 show the trajectory of iceberg C20 obtained from the Brigham Young University (BYU) "Antarctic Iceberg Tracking Database" (http://www.scp.byu.edu/data/ iceberg/database1.html last accessed: 07 August 2012). Iceberg C20 calved off the Shackleton Ice Shelf (Figure S2), after which it traveled westward within the ASC. As C20 started drifting northward, it entered the eastward ACC. The comparison of satellite observations and hydroacoustic event locations in Figure 3 shows a clear spatial and temporal correlation between the two data sets. In particular, the highest density of hydroacoustic events (between day 400 and 430) match with the satellite-derived iceberg track. 

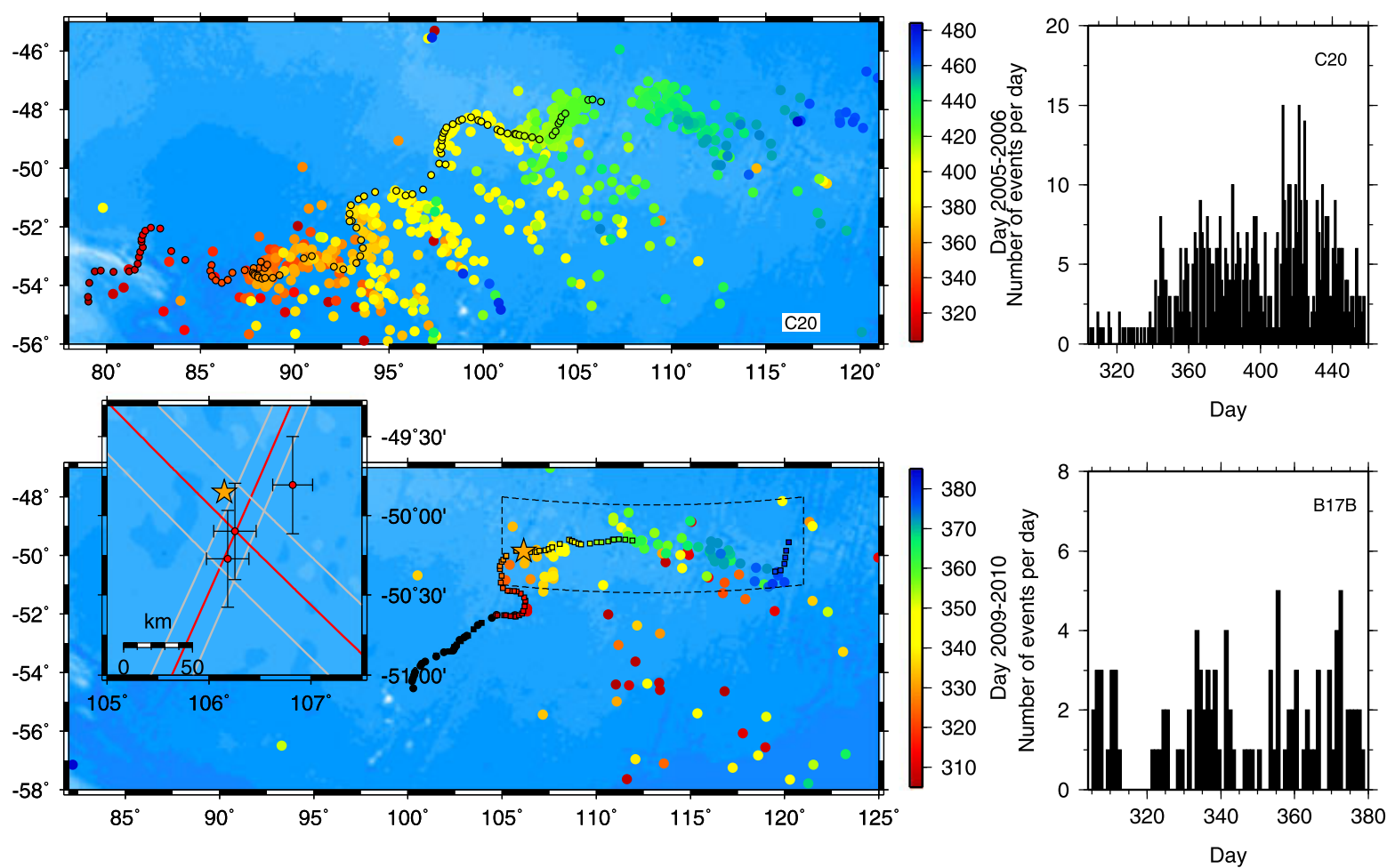

Figure 3. Map showing the locations estimated from detections at H01W and H08S (colored circles). The colors indicate the day in 2005 and 2006 (+365) for (top) C20 and (bottom) B17B for 2009 and $2010(+365)$. The colored symbols with black edges are satellite-derived locations of icebergs; circles are from the BYU database while squares are from Moderate Resolution Imaging Spectroradiometer (MODIS) images. The solid black dots for B17B indicate its earlier path. The yellow star is the location of B17B on 29 November 2009 from a MODIS image; the hydroacoustic locations and uncertainties on this day are given in the inset. The red lines are the back azimuths from H08S and H01W for one specific event (red dot) and the $\pm 0.4^{\circ}$ uncertainties (gray lines). The errors in the locations (red dots) are given as vertical and horizontal bars. The histograms give the number of hydroacoustic events per day. All events shown for C20 are used for the calculation of the histogram; for B17B only, the events within the area enclosed by the dashed lines are used.

[15] To confirm the correlation between satellite and hydroacoustic locations, the track of a second iceberg, known as B17B (Figure S3), is also analyzed.

[16] A set of hydroacoustic detections at H01W that exhibit slowly varying back azimuths (see Figure 2) correspond to the movement of iceberg B17B between November 2009 and January 2010. In comparison with C20, this acoustic feature is less well pronounced at H08S, but hydroacoustically derived locations again identify an eastward moving source in the southern Indian Ocean (Figure 3, bottom). However, there are only a few data points for this iceberg in the BYU database; therefore, the correlation is less clear.

[17] Note that the overall time duration of hydroacoustic observations for B17B is shorter than that for $\mathrm{C} 20$. In addition, the hydroacoustic activity generated by B17B appears to be located in the proximity of the major iceberg; there are no trails of hydroacoustic locations to the southeast as for iceberg C20. The few events to the southeast of the track are not associated with B17B as their occurrence is separated from the transit of the iceberg by periods of days to weeks.

[18] To test whether the extended hydroacoustically derived locations were accurate, we compared the locations with high-resolution satellite images. An observation made with the MODIS (Moderate Resolution Imaging Spectroradiometer) aboard NASA satellites shows B17B as a 22 by $10 \mathrm{~km}$ iceberg at $49.85^{\circ} \mathrm{S}, 106.15^{\circ} \mathrm{E}$ on 29 November
2009 (see: http://earthobservatory.nasa.gov/NaturalHazards/ view.php?id=41898, last accessed: 07 December 2012). This location is shown as a star symbol in Figure 3, alongside locations of the main sections of iceberg B17B obtained interactively from images of the MODIS. These MODISderived positions correspond to the centroid of the main iceberg sections and have an accuracy of $\sim 1+\mathrm{km}$. These locations match with the hydroacoustically derived locations. The latter gives confidence that the hydroacoustically derived extended locations are associated with B17B and C20; the advantage of the hydroacoustic locations is they can be made automatically in all meteorological conditions.

\section{Discussion}

[19] The results clearly show that hydroacoustic arrivals, detected at stations located thousands of kilometers from the ACC, can assist in tracking large icebergs. Here we discuss the results and show how hydroacoustic observations can be used for iceberg monitoring purposes for these two large icebergs.

[20] 1. Hydroacoustic signals provide a method of extending iceberg tracks once not resolvable by microwave backscatter. For both $\mathrm{C} 20$ and B17B, hydroacoustic signals are observed after the last reported location in the BYU tracking database (the threshold is about $4-5 \mathrm{~km}$ for the 
iceberg's size), and the hydroacoustically estimated locations extend to the northeast in the direction of flow. In the two cases studied, the satellite tracks were lost due to storms which obscured their appearance against the ocean (D. G. Long, personal communication, 2012). Therefore, hydroacoustic signals provide iceberg location information during meteorological conditions which obscure satellite observations. It should be noted that storms may lead to an increased breakup of icebergs and hence more acoustic signals.

[21] However, it is also found that there are periods when large icebergs do not radiate hydroacoustically. For example, the most easterly MODIS locations during early 2010 correspond to a large fragment that broke from B17B, moving to the north. The acoustic activity is the highest during and just after the break off after which it becomes acoustically quiet.

[22] 2. The rate of hydroacoustic signal generation provides a qualitative indication of iceberg breakup. For both $\mathrm{C} 20$ and $\mathrm{B} 17 \mathrm{~B}$, the number of events increased toward the end of the iceberg's lifetime. However, there were significant differences between the acoustic activity. C20 emitted hydroacoustic signals during the whole path, with the number of events strongly increasing from day 410 (14 February 2006); B17B emitted detectable hydroacoustic waves only during its last stages (see histograms in Figure 3). Observations show that $\mathrm{C} 20$ shed many small icebergs along the path, while B17B shed fewer icebergs until near the end of the path (D. G. Long, personal communication, 2012); hydroacoustic activity appears to increase during the breakup phases of the icebergs. The calving of smaller icebergs and the collision of icebergs against each other is a likely source of acoustic waves, rather than a solitary iceberg floating in the ocean. In that respect, the MODIS and hydroacoustically derived locations in the inset of Figure 3 do not necessarily have to coincide. In addition, there are events to the SE of the main iceberg that occur over the same time period (see Animation S1). These are related to smaller icebergs that have calved from $\mathrm{C} 20$ and drifted eastward rather than following $\mathrm{C} 20$ so that the two groups diverge over time. C20 calves many small icebergs because of pre-existing fractures that developed as the Denman Glacier flowed from the grounded ice sheet into the floating part that passes through the Shackleton Ice Shelf. This created a tessellated surface pattern with elements of about $2 \mathrm{~km}$ across. Calving occurred preferentially along some of these fracture lines.

[23] Furthermore, the calculations of hydroacoustic arrival azimuth residuals, from earthquakes, showed that deviations in the area of interest are in the range of $\pm 1^{\circ}$. The deviations are distributed around zero, so the systematic offset of hydroacoustic locations to the southeast of C20 is a source characteristic, i.e., acoustic activity from smaller icebergs. This fits with the observation that $\mathrm{C} 20$ calved many small icebergs along its path, while B17B, which is a rather uniform slab that calved from the Ross Ice Shelf, such that it did not undergo continuous disintegration and does not have associated hydroacoustic locations to the southeast.

[24] The ability to assist in iceberg monitoring is dependent upon the accuracy of the locations and the detail of iceberg movement that can be extracted from hydroacoustic events:

[25] 1. The accuracy of the acoustic locations, for the particular case of $\mathrm{B} 17 \mathrm{~B}$, can be assessed with the above 29 November 2009 MODIS satellite image. The error in the observed back azimuths is on the order of $0.4^{\circ}$. This consists of a $0.2^{\circ}$ error due to motions of the hydrophones and $0.2^{\circ}$ due to horizontal refractions by inhomogeneities in the oceans [ $L i$ and Gavrilov, 2009], a value confirmed by Green et al. [2013]. The inset in the lower frame of Figure 3 shows the location of the iceberg from the MODIS image and the hydroacoustic detections on 29 November 2009. The back azimuths from H08S and H01W for the closest hydroacoustic location to the iceberg are shown, with the uncertainties. In this case, the hydroacoustically derived location is separated from the iceberg by approximately $\pm 0.5^{\circ}$. This value provides an indication of the location accuracy, assuming the event was generated at the main iceberg. Since ground-truth information regarding iceberg location is sparse, combined with the extended source region, it is hard to give a more detailed error estimate.

[26] 2. More sophisticated location algorithms will give confidence in the event locations. In the present study, two velocities $(1485$ and $1480 \mathrm{~m} / \mathrm{s})$ are assumed, yet the velocity is known to increase toward more northern latitudes due to the increase in temperature. Using our location methodology, the results of incorporating a more detailed velocity model will be limited, since the locations are determined from cross bearings with the $\Delta t$ threshold used to check temporal association. The values of $\Delta t$ will change by using a multidimensional velocity model, resulting in some locations being discarded and some new ones being added. The slight negative value of the mean of $\Delta t$ will move toward zero. The observations of moving icebergs, and high hydroacoustic event rates associated with iceberg breakup will not change significantly. A future in-depth study of the event waveform characteristics may also improve confidence in the arrival times, thereby improving the location accuracy. Furthermore, the waveforms might also reveal the type of events, for example, to distinguish between fracturing, collisions, or rubbing.

\section{Conclusions}

[27] We provide evidence that long-range hydroacoustic observations were detected from the transport, and breakup, of two large icebergs within the ACC. A more in-depth study designed to identify detection thresholds and the processes generating such signals will provide a quantitative assessment of the utility of hydroacoustic signals for iceberg monitoring. In addition, the recordings provide temporal information about the breakup of these icebergs; mechanical phenomena such as fracturing and collision produce detectable acoustic signals, but are not continuously identifiable from satellite recordings. The acoustic signature of two very large icebergs, $\mathrm{C} 20$ and $\mathrm{B} 17 \mathrm{~B}$, drifting within the ACC were identified on IMS hydrophone array recordings in the Indian Ocean. C20 was monitored hydroacoustically for 120 days during the Austral summer of 2005-2006. Hydroacoustic signals generated by B17B were associated and located for 70 days during 2009-2010. The two icebergs exhibited contrasting acoustic time series; C20 emitted semicontinuous hydroacoustic waves, while B17B was acoustically active in the later stages of its trajectory. In addition, hydroacoustic locations associated with $\mathrm{C} 20$ were distributed both at the satellite-derived iceberg location and in an area to the southeast of the iceberg, while for B17B, the hydroacoustic locations were co-located with the main iceberg. These observations are in agreement with the calving 


\section{EVERS ET AL.: REMOTE ACOUSTIC SENSING OF TWO ICEBERGS}

behavior: $\mathrm{C} 20$ shed many smaller pieces during transport, while B17B shed fewer icebergs until close to the end of its existence. This is consistent with the hypothesis that hydroacoustic activity at icebergs is mainly associated with breakup phases, with hydroacoustic events being generated by calving and collision both at the main iceberg and within the ice debris field, where smaller icebergs can also generate acoustic waves when rubbing against each other. Furthermore, hydroacoustic localization is not affected by meteorological phenomena that can preclude satellite tracking. In conclusion, long-range, i.e., thousands of kilometers, hydroacoustic observations with multiple arrays can complement satellite tracking of icebergs, as shown for these two very large icebergs.

[28] Acknowledgments. The CTBTO and station operators are thanked for the high quality of the IMS data and products. M. K. Prior (CTBTO) is thanked for his input on technical and observational issues. J. Schweitzer (NORSAR) is thanked for providing the cross-bearing algorithm. D. G. Long (BYU) is thanked for his comments on the behavior of the icebergs and satellite detection. Figures were made with the GMT [Wessel and Smith, 1991].

[29] The Editor thanks two anonymous reviewers for their assistance in evaluating this paper.

\section{References}

Chapp, E., D. R. Bohnenstiel, and M. Tolstoy (2005), Sound-channel observations of ice-generated tremor in the Indian Ocean, Geochem. Geophys. Geosyst., 6, Q06003, doi:10.1029/2004GC000889.

De Groot-Hedlin, C. D., and J. Orcutt (2001), Monitoring the comprehensive nuclear-test-ban treaty: Hydroacoustics, Pure Appl. Geophys., 158, $412-626$.

Gavrilov, A., and B. Li (2011), Location of ice noise sources in Antarctica, Proceedings of Underwater Acoustic Measurements Conference, Kos, Greece.
Green, D. N., L. G. Evers, D. Fee, R. S. Matoza, M. Snellen, P. Smets, and D. Simons (2013), Hydroacoustic, infrasonic and seismic monitoring of the submarine eruptive activity and sub-aerial plume generation at South Sarigan, May 2010, J. Volcanol. Geotherm. Res., 257, 31-43.

Guilbert, J., J. Vergoz, E. Schisselé, A. Roueff, and Y. Cansi (2005), Use of hydroacoustic and seismic arrays to observe rupture propagation and source extent of the $M_{w}=9.0$ Sumatra earthquake, Geophys. Res. Lett., 32, L15310, doi:10.1029/2005GL022966.

Jensen, F. B., W. A. Kuperman, M. B. Porter, and H. Schmidt (2000), Computational Ocean Acoustics, 1-59 pp., Springer, New York.

Li, B., and A. Gavrilov (2009), The significance of horizontal refraction effect for back-azimuth estimation from the CTBT hydroacoustic stations, Proceedings of International Scientific Studies Conference, Vienna, Austria.

Li, B., and A. N. Gavrilov (2006), Hydroacoustic observations of Antarctic ice disintegration events in the Indian Ocean, Proceedings of ACOUSTICS 2006, Christchurch, New Zealand.

Prior, M. K., O. Meless, P. Bittner, and H. Sugioka (2011), Longrange detection and location of shallow underwater explosions using deep-sound-channel hydrophones, IEEE J. Oceanic Eng., 36, $703-715$.

Prior, M. K., D. J. Brown, G. Haralabus, and J. Stanley (2012), Long-term monitoring of ambient noise at CTBTO hydrophone stations, Proceedings of Underwater Acoustic Measurements Conference, Edinburgh, U. K.

Snellen, M., L. G. Evers, and D. G. Simons (2012), Extracting ocean sound speeds using naturally generated noise with the IMS monitoring system, Proceedings of Underwater Acoustics Measurements Conference, pp. 756-763, Edinburgh, U.K.

Stuart, K. M., and D. G. Long (2011), Tracking large tabular icebergs using the SeaWinds Ku-band microwave scatterometer, Deep Sea Res. Part II 58, 1285-1300.

Talandier, J., O. Hyvernaud, E. A. Okal, and P.-E. Piserchia (2002), Longrange detection of hydroacoustic signals from large icebergs in the Ross Sea, Antarctica, Earth Planet. Sci. Lett., 203, 519-534.

Talandier, J., O. Hyvernaud, D. Reymond, and E. A. Okal (2006), Acoustic signals generated by parked and drifting icebergs in the Southern Indian and Pacific Oceans, Geophys. J. Int., 165, 817-834.

Wessel, P., and W. H. F. Smith (1991), Free software helps map and display data, EOS Trans. $A G U, 72,441-446$. 